\title{
Editorial
}

\section{Cuatro años de ARENA: la punta del iceberg}

ARENA ha cumplido cuatro años como gobierno, pero su existencia como partido se remonta al inicio del conilicto bélico salvadorefio. Es esto lo que se quiere significar con la imagen del iceberg. En realidad, hay algo más en el uso de esla imagen, porque el iceberg tiene dos partes, la visible y la sumergida, aunque ambas estén hechas del mismo componente. El componente general, de acuerdo al lema del partido, es cambiar para mejorar. Hay que cambiar la historia de EI Salvador y el cambio dependerá de la imagen que ARENA tenga de la misma historia. Esla imagen es militarista (sudor $y$ sangre), inspirada por su fundador; $y$ el fin de la historia es que El Salvador sea la tumba del comunismo: alianza nacionalista contra invasión internacional. La alianza nacionalista será necesariamente alianza militarista.

En cuanto alianza militarisla los inspiradores de ARENA bien hubieran podido, a su vez, inspirarse en la proclama de los jóvenes oficiales militares que dieron el golpe de estado en octubre de 1979. Al presentar sus razones históricas estos jóvenes militares le estaban olreciendo en bandeja a ARENA un programa económico a favor del verdadero pueblo salvadoreño. Por ello es ilustrativo esquematizar la proclama militar1979. Se acusa al gobierno porque "ha violado los derechos humanos del conglomerado. Ha lomentado y tolerado la corrupción en la administración pública y de la justicia. Ha creado un verdadero desastre economico y social. Ha despresligiado profundamente al pais y a la noble institución armada. Convencida de que los problemas anteriormente mencionados son el produclo de anticuadas estructuras económicas, sociales y politicas que han prevalecido tradicionalmente en el pais, las 
que no ofrecen para la mayoria de la población las condiciones mínimas necesarias para que puedan realizarse como seres humanos... Conocedora con certeza de que los gobiernos de lumo, produclos a su vez de escandalosos Iraudes electorales, han adoplado programas inadecuados de desarrollo, en los que los tímidos cambios de estructuras planleados han sido trenados por el poder económico y político de sectores conservadores... Firmemente convencida de que las condiciones anteriores son las causa del caos económico y social y de la violencia que se está padeciendo en la actualidad..., por tanto la Fuerza Armada decide... crear las condiciones para que en nuestro país podamos todos los salvadorefios tener paz y vivir acorde a la dignidad del ser humano... Los lineamienlos de este programa de emergencia son los siguientes: I) cese a la violencia y a la corrupción; II) garantizar la vigencia de los derechos humanos; ill) adoptar medidas que conduzcan a una distribución equilaliva de la riqueza nacional, incrementando al mismo tiempo, en forma acelerada, el producto territorial bruto: a) creando bases firmes para iniciar un proceso de reforma agraria; b) proporcionando mayores oportunidades económicas para la población, mediante retormas en el sector linanciero, tribulario y comercio exterior del pais; c) adoptando medidas de protección al consumidor para contrarrestar los efeclos de la inflación; e) reconocimiento y garantizando el derecho a la vivienda, educación y salud de lodos los salvadoreños"... (ECA; 1979; pp. 10171018). ARENA tenía en sus manos un programa de inspiración militar que le hubiere ahorrado la firma de los acuerdos de paz...

Para el partido-ARENA no era esa la verdadera historia del pueblo salvadoreño; el verdadero enemigo es el comunismo internacional. La amenaza viene de fuera, pero ya está incrustada dentro. La respuesla es: sudor-sangre-guerra y lumba. La parte sumergida del iceberg-ARENA es el negalivo de la proclama de los jóvenes militares-1979. Dos lecturas mililares opuestas sobre la misma realidad de EI Salvador. La lectura de ARENA se hace desde los ojos de los civiles y mililares influyentes. La proclama de los oficiales militares-1979 es el anlejuicio de ARENA y el inlorme de la Comisión de la Verdad conlirmará la sentencia.

El verdadero enemigo no son sólo las ideas sino lambién las reformas decreladas: los enemigos son dos: los subversivos y la democracia cristiana. Al entrar en la fase preelectoral-1989 ARENA proclamará que el caos económico-social se debe a la triple reforma bancaria, agraria y del comercio exterior y a la inlromisión de una administración pública ineficiente y corrompida. Su hábil publicidad utiliza los mismos argumentos para autodelenderse y para atacar a la administración anterior. 
La adversa coyunlura internacional explica que de 1989 a nuestros dias las exportaciones tradicionales hayan visto deteriorados sus precios y cantidades poniendo en siluación deficitaria a los gremios correspondientes y trabando el proceso de recuperación del modelo oficial. La misma publicidad de autodefensa silencia que la adversa coyuntura internacional redujo a la mitad el valor en dólares de nuestras exportacio- nes de 1980 a 1989, incrementando sensiblemente el costo de las importaciones. Se critica el desastre de la nacionalización bancaria que deriva en una sobregirada moraloria de $\$ 2.300$ millones en 1989. La misma publicidad silencia que no hubo una nacionalización sino una desnacionalización bancaria, donde afiliados de ARENA tuvieron gran arte y parte. A lo largo de la década se llevó a cabo una patriólica fuga de capital, alimentada por las remesas de emigrantes, que se aproximó al monto de la deuda externa. Ciertamente la moraloria bancaria de 1989 alcanzó los $\$ 2.300$ millones; los diarios malutinos y vespertinos tuvieron a bien editar la lista de las grandes empresas como principales comprometidos en esta mora y desnacionalización bancaria. En castigo, la ley de privatización bancaria les ha concedido el oligopolio de la administración del ahorro nacional y de las remesas de emigrantes.

Se argumentará que en la administración anterior hubo mucha corrupción, pero la acusación olvida que para que haya corrupción hacen talta dos: el que da y el que recibe, el que pide y el que consiente, el que olorga y el que no devuelve. Tan culpables son los prestamistas como los prestatarios. Tampoco vale recurrir al lamento de que una mayor proporción o incremento del crédito se desvió hacia el seclor público con merma del sector privado. Al argumento se le reluerce lácilmenle el brazo: sin repetir que buena parte del ahorro se había asegurado fuera, a juzgar por el elevado monlo de la moraloria refinanciada no falló el suficiente crédito al sector privado, sino que más bien falló el crédilo del sector privado a la hora de reembolsar los préslamos. Por otra parte, quienes volaron por la guerra como la solución, inconscientemente volaron por la deuda exlerna, el délicit inlerno y el creciente crédito al Estado. La década de los 80 fue una economia de guerra, no de democracia cristiana, como lo han enlendido algunos de ARENA con la olensiva de 1989, admitiendo el empate militar, para salvar la economia.

Sin adjudicarles el calificalivo de prolelas, la proclama de los jóvenes militares-1979 hizo la radiogratia del iceberg-ARENA en sus partes visible y sumergida. Los jóvenes oficiales no pertenecian a la internacional socialista, sino que pretendian cerrar la intromisión comunista delendiendo los derechos y reclamos de las clases populares. Por eso hemos preferido recurrir a las cláusulas de esta proclama militar y no a las 
recriminaciones de la UNOC-UNTS... para no despertar suspicacias partidistas. ARENA escogió y propició la vía falsa de la guerra que, aparte de la "cronología de la violencia "recorrida por la Comisión de la Verdad, profundizó el caos económico nacional. Ellos no son expecladores sino coautores de la descomposición civil y económica, que viene ulilizando en su propaganda preelectoral y en su actual tase gubernamental. Por no haber adoptado la proclama de los jóvenes militares-1979 se han visto forzados a firmar cosas similares en los acuerdos de paz, aunque no con el parabien de todos sus afiliados.

El gran error de ARENA ha sido y sigue siendo no querer ver ni decir la verdad. Por ello su equivocada política del "perdón-olvido" ante el informe de la Comisión de la Verdad. También es quebradizo su iceberg-económico; realzan los logros superticiales macroeconómicos, como punta del iceberg que presentan a las insliluciones financieras internacionales y a las clases beneficiadas, pero no logran dar con la solución económica y social para la población mayoritaria sumergida en virtud del mismo modelo económico. De haber escuchado la verdad el mismo plan de reconstrucción nacional se hubiera inaugurado hace trece años: lambién esto es parte de la década perdida. Por su historia militarista de minorias influyentes, por su credo neoliberal económico, por su silencio y tergiversación de la verdad ellos mismos eslán generando la expeclativa de que el iceberg-ARENA va a liquarse...

Con la propuesta de gobierno 1994-1999 (La Prensa Gráfica; 30mayo-93: pp. 25-28) ARENA abandona su terminología belicista presentándose como el partido de la solidaridad y coparticipación. El nuevo candidato presidencial, cuya foto preside el desplegado de cuatro páginas, abandona el relo agresivo de "los arrollaremos" adoptando la imagen conciliatoria de "los arrullaremos" con muchas promesas de cambio. Este pronunciamiento serviría como puntos de agenda para una aulocrítica del partido-ARENA, pero el arte de la publicidad imperante lo ulilizará para convencer a ingenuos e indecisos. De todas formas hay que admilir que su parte introductoria, los principios de gobierno, nos presenla un conjunto de valores o premisas fundamentales para cualquier programa de nación. Se pretende "un cambio de mentalidad" (democracia)," un cambio de aclilud" (sociedad libre y solidaria) y "un cambio de enfoque" (ampliar las 1ronleras productivas). Estas premisas se traducen en objetivos y estrategias en las áreas de acción política, del Estado de Derecho y del desarrollo económico y social. El arliculado y las promesas se extienden hasta cualro páginas. "Los arrullaremos"...

Sin duda otros partidos utilizarán este serial de promesas para convertirlas en arma crítica porque el humanismo no ha sido el lado luerte 
del partido-ARENA. A menos que se de un proceso de conversión, del cual no hay signos, no encajan bien en el pasado de este partido estos principios introductorios, que los resumimos en trases sueltas. "La dignidad de la persona humana, creada a imagen y semejanza de Dios; la libertad, la justicia y el orden social; el derecho a la vida y a la propiedad; la educación y la salud como derechos fundamentales; la igualdad de oportunidades desde el inicio mismo de la vida; el bien común como fundamenlo de lodos los esfuerzos; un sólido Estado de Derecho; desarrollo democrático en un proceso de paz; Dios, Patria y Libertad..."

¿Encajan estos principios en el historial de ARENA o son una autocrítica en orden a una conversión? -Después de las resistencias al cumplimiento de los acuerdos de paz, de la oposición visceral al inlorme de la Comisión de la Verdad, de la precipitada Ley de Amnistia, de la permisibilidad o coautoria en la persecución religiosa y de los gravámenes sociales derivados del modelo económico..., la respuesta se inclina por la negativa. Sin embargo, estos pronunciamientos tienen un gran valor: sin estos principios humanos, hoy por hoy bastanle irreales, no puede haber un desarrollo económico y social. Esto no es un relo para un partido sino para lodos los grupos o movimientos progresistas de nuestra sociedad.

Hay otra pareja de variables dilusas pero realislas que comienzan a aparecer en los pronunciamientos de los partidos conlendientes: "solidaridad y compartición". En la propuesta-ARENA puede leerse: "solidaridad y coparticipación de trabajadores-empresarios y gobierno (aunque la historia del FES convierla esta línea en letra mojada); un sector privado solidario en el marco de un amplio acuerdo hislórico; solidaridad en lodos los seclores progresistas; lograr la plena armonia entre trabajadores y empresarios (y ¿por qué no al revés?); la participación de loda la población en el beneficio del desarrollo económico: participación, en fin, "recogiendo las sugerencias y opiniones para que a través de la participación ciudadana cumplamos junlos el Plan Nacional de Gobierno".

Hecha la presente declaración, el fiscal inlerroga al tesligo. Tres dias anles La Convergencia había edilado una simple página programática, presidida por la folo del Dr. Rubén Zamora, (La Prensa Grálica; 27mayo-93; p. 57). Esla simple página, a modo de marea alla, desmorona el castillo de arena: "El Salvador se encuentra en un periodo de Iransición caracterizado por el paso del viejo régimen autorilario y excluyenle hacia un régimen democrático y participativo... Se hace impostergable una renovación de la estrategia de desarrollo y de la polílica económica, que consolide los logros, acelere y vuelva realidad las polencialidades de todos los seclores sociales y redelina un lipo de gestión económica 
para todos en el marco de participación y concertación efectiva" ...Sea dicho de paso que la imagen de Rubén Zamora es visla como un serio compelidor: ¿qué olra explicación se puede dar a esas burdas Arenillas que, aparte de tener muy poca gracia, no entroncan con un serio proceso preelecloral y son más propias de las maras estudianliles?...

Todas estas son variables o principios lundamentales para un programa de nación. La compelencia política se ha iniciado y hay varios interrogantes en el horizonte. La esperanza es la única propiedad privada que les queda a los más pobres de los pobres. Las ventajas comparativas de ARENA son las debilidades de sus opositores y enconlramos bastanles debilidades. Hay Iricciones y divisiones denlro de algunos parlidos; hay ocultamiento de la verdad y pretensiones de prebendas; no en lodos se percibe una apertura de gobierno coparticipado y se busca más el poder que el servir. Todo esto nos puede llevar a un quinquenio de proteslas y deterioro social. Es menester que los partidos y movimientos progresislas pongan por delante los inlereses de la nación y no las venlajas propias. Nos quedamos esperando una respuesta: ¿cuál o cuáles de los partidos darán pruebas eficienles de apoyar e inlegrar a los grupos progresistas compromelidos con el lema de "cambiar para mejorar"?... 